\title{
Pesticide Removal from Aqueous Solutions by Adding Salting Out Agents
}

\author{
Fátima Moscoso $^{1,2}$, Francisco J. Deive ${ }^{1}$, José M. S. S. Esperança ${ }^{2}$ and Ana Rodríguez ${ }^{1, *}$ \\ 1 Department of Chemical Engineering, University of Vigo, 36310 Vigo, Spain; \\ E-Mails: fatimamoscoso@uvigo.es (F.M.); deive@uvigo.es (F.J.D.) \\ 2 Instituto de Tecnologia Química e Biológica, Universidade Nova de Lisboa, Av. da República, \\ 2780-756 Oeiras, Portugal; E-Mail: jmesp@itqb.unl.pt \\ * Author to whom correspondence should be addressed; E-Mail: aroguez@uvigo.es; \\ Tel.: +34-986-812-213; Fax: +34-986-812-383.
}

Received: 16 September 2013; in revised form: 12 October 2013 / Accepted: 12 October 2013 /

Published: 18 October 2013

\begin{abstract}
Phase segregation in aqueous biphasic systems (ABS) composed of four hydrophilic ionic liquids (ILs): 1-butyl-3-methylimidazolium methylsulfate and 1-ethyl-3-methylimidazolium methylsulfate $\left(\mathrm{C}_{\mathrm{n}} \mathrm{C}_{1} \mathrm{im}_{1} \mathrm{SO}_{4}, n=2\right.$ and 4), tributylmethyl phosphonium methylsulfate $\left(\mathrm{P}_{4441} \mathrm{C}_{1} \mathrm{SO}_{4}\right)$ and methylpyridinium methylsulfate $\left(\mathrm{C}_{1} \mathrm{Py} \mathrm{C}_{1} \mathrm{SO}_{4}\right)$ and two high charge density potassium inorganic salts $\left(\mathrm{K}_{2} \mathrm{CO}_{3}\right.$ and $\left.\mathrm{K}_{2} \mathrm{HPO}_{4}\right)$ were determined by the cloud point method at $298.15 \mathrm{~K}$. The influence of the addition of the selected inorganic salts to aqueous mixtures of ILs was discussed in the light of the Hofmeister series and in terms of molar Gibbs free energy of hydration. The effect of the alkyl chain length of the cation on the methylsulfate-based ILs has been investigated. All the solubility data were satisfactorily correlated to several empirical equations. A pesticide (pentachlorophenol, PCP) extraction process based on the inorganic salt providing a greater salting out effect was tackled. The viability of the proposed process was analyzed in terms of partition coefficients and extraction efficiencies.
\end{abstract}

Keywords: pentachlorophenol; ionic liquids; aqueous biphasic systems; extraction; potassium inorganic salts 


\section{Introduction}

Organochlorine micropollutants such as insecticides (lindane, heptachlor, DDT, etc.) are the subject of a great environmental and health concern since they remain in soils without significant degradation up to 30 years after their use. Among them, pentachlorophenol (PCP) is considered as an outstanding example, since it has been used in ropes, paints adhesives, brick walls, and especially as fungicide and insecticide for wood preservation. Thus, about 36 million PCP-treated utility pine poles are in service across the United States [1], which poses an undoubted environmental risk. Recent environmental water legislation has restricted or even banned the utilization of this group of pesticides, limiting the maximum allowable concentration in drinking water to $0.001 \mathrm{mg} / \mathrm{L}$ [2]. Therefore, the need to investigate efficient remediation techniques for the removal of this kind of pollutants has furthered the emergence of physico-chemical (chemical precipitation, lime coagulation, ion exchange, reverse osmosis, volatilization, photolysis, and adsorption) or biological (biosorption or biodegradation) techniques. Nevertheless, these methods present several shortcomings such as incomplete removal, sludge generation, time and energy requirements or high operating costs [3].

One of the viable alternatives for pesticides removal from aqueous solutions is the use of liquid-liquid extraction. In this sense, the strategies based on aqueous biphasic systems (ABS) where a complex competition between the polymers or salts for the water molecules [4] and specific interactions between polymers and salts have recently become an attractive option due to decisive reasons: (i) they are considered a suitable method for the separation of biomolecules [5-7], metal ions [8], and drug molecules [9]; (ii) they involve low cost and energy requirements; (iii) they entail rapid phase disengagement [10-12].

Nowadays, greener alternatives have been developed, and ionic liquids (ILs)-based ABS have been reported since 2003, when the first work on this topic was published [13]. From this year on, several papers have focused on the molecular phenomena governing IL-based ABS, varying from partition of amino acids to pharmaceuticals and biomolecules [11,14-16]. These molten salts pose an innovative alternative to conventional organic solvents, and they have opened new opportunities in extraction processes at industrial scale [17]. These molten salts are showing a tremendous growth on a diversity of fields, both fundamental and technological, making them an obvious choice for the current study. These neoteric solvents are starting to find their way into a plethora of industrial sectors, ranging from electrochemistry to biocatalysis [18]. The reason for their appeal lies in their unique properties such as, very low volatility, inflammability and recyclability [19-21]. One of the most promising characteristics of ILs is their tunability, meaning that the existence of a great number of possible combinations of cations and anions allows the design of ILs suitable for a specific industrial process. Nevertheless, although the low vapor pressure of ILs may help to reduce the air pollution, there are some ecotoxicity issues that should be taken into account prior to their use at industrial scale [22,23].

Up to date, PCP extraction was tackled only for hydrophobic ILs [24-27], so this work is the first time that hydrophilic ILs have been proposed to this end. The first purpose of this work is to provide information concerning the experimental phase segregation behavior of mixtures containing methylsulfate-based ILs, potassium inorganic salts and water. In this sense, the presence of ILs in the formation of ABS influences the possibility of changing their polarities and affinities. The proper combination cation-anion is the main advantage offered by these systems, in comparison with 
conventional ABS, where these properties are controlled by the amount of water in the phases. This information is vital to suitably understand separation processes and for the design and optimization of any extraction unit.

Methylsulfate-imidazolium-based ILs were chosen as models for this work since they belong to one of the most widely used families of ILs. Furthermore, they exhibit moderate viscosity, chemical stability, and low melting point temperature [28]. Additionally, phosphonium and pyridinium families were also investigated as typical commercial families of ILs. Among their specific characteristics the low viscosity of the selected ILs will favor the mass transfer and then the short time required for the ABS formation. Another important issue addressed in this work refers to the effect of the type and size of the cation for phase segregation in the presence of two inorganic salts, dipotassium hydrogen phosphate $\left(\mathrm{K}_{2} \mathrm{HPO}_{4}\right)$, and potassium carbonate $\left(\mathrm{K}_{2} \mathrm{CO}_{3}\right)$. The inorganic salts were selected due to their different degrees of kosmotropicity, thus licensing to map the immiscibility region. The experimental solubility curves of the hydrophilic ILs were correlated through several empirical models and the Effective Excluded Volume theory (EEV) and the results were discussed in terms of standard deviations. The proposed systems were used to elucidate their potential to extract pentachlorophenol as model persistent organic pollutant.

\section{Results and Discussion}

The experimental binodal curves for the ternary mixtures composed of aqueous solutions of the ILs $\left(\mathrm{C}_{\mathrm{n}} \mathrm{C}_{1} \mathrm{im} \mathrm{C}_{1} \mathrm{SO}_{4}, n=2\right.$ and $4, \mathrm{P}_{4441} \mathrm{C}_{1} \mathrm{SO}_{4}$ and $\left.\mathrm{C}_{1} \mathrm{Py} \mathrm{C}_{1} \mathrm{SO}_{4}\right)$ and inorganic salts $\left(\mathrm{K}_{2} \mathrm{CO}_{3}\right.$ and $\left.\mathrm{K}_{2} \mathrm{HPO}_{4}\right)$ are summarized in Table $\mathrm{S} 2$ and are plotted in Figure 1. The information coming from the literature [29] indicates that just experimental data related to the system composed of $\mathrm{C}_{2} \mathrm{C}_{1} \mathrm{im}_{1} \mathrm{CO}_{4}$ and $\mathrm{K}_{2} \mathrm{HPO}_{4}$ are available and a very good agreement is obtained.

Figure 1. Solubility curves of the aqueous biphasic systems (ABS) formed by ILs and inorganic salts: $(\Delta) \mathrm{K}_{2} \mathrm{HPO}_{4}$; (口) $\mathrm{K}_{2} \mathrm{CO}_{3}$; (Red) $\mathrm{P}_{4441} \mathrm{C}_{1} \mathrm{SO}_{4}$; (Blue) $\mathrm{C}_{1} \mathrm{Py} \mathrm{C}_{1} \mathrm{SO}_{4}$; (Black) $\mathrm{C}_{4} \mathrm{C}_{1}$ im $\mathrm{C}_{1} \mathrm{SO}_{4}$; (Green) $\mathrm{C}_{2} \mathrm{C}_{1}$ im $\mathrm{C}_{1} \mathrm{SO}_{4}$. Solid lines represent the fitting to the best empirical equation.

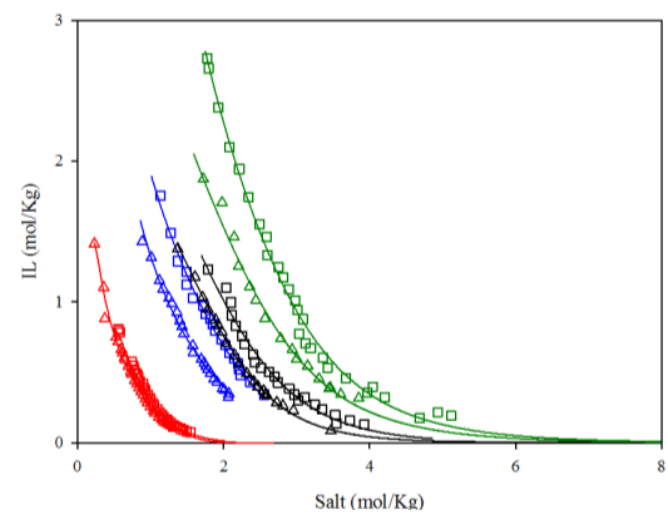

A visual inspection of the experimental curves reveals that it is possible to analyze the role of the potassium salts as phase promoters in aqueous solutions of methylsulfate-based ILs from the point of view of the inorganic cation and the molar entropy of hydration. The size and type of the IL cation was also used to understand the observed phase segregation. 
Two empirical three-parameter equations [30] were used to correlate the solubility data of the selected IL-based systems. On the one hand, the characteristic exponents $n$ and $m$ were fixed to 0.5 and 3 , respectively as it was proposed by the authors. On the other hand, a five-parameter equation was also used, as proposed recently by Deive et al. [31].

$$
\begin{array}{lllll}
w & a & \left(b w^{n}\right. & \left.c w^{m}\right) \\
w & d & \left(\begin{array}{lll}
w & f
\end{array}\right) & e
\end{array}
$$

where $w_{1}$ and $w_{2}$ are the IL and potassium inorganic salt mass composition, respectively, and $a, b, c, d$, $e, f, n$ and $m$ are the fitting parameters.

The SOLVER function provided by Microsoft EXCEL was the tool used to fit the constants so that the objective function was minimized. The standard deviations were calculated by applying the following expression:

$$
\sigma=\left(\sum_{\mathrm{i}}^{\mathrm{n}_{\mathrm{DAT}}}\left(z_{\text {exp }}-z_{\text {adjust }}\right)^{2} / n_{\mathrm{DAT}}\right)^{1 / 2}
$$

where the property values and the number of experimental and adjustable data are represented by $z$ and $n_{\text {DAT }}$, respectively.

The values of the coefficients obtained from the correlation of the experimental data along with the corresponding deviations are given in Tables 1 and 2. The correlation equation is also presented in Figure 1 together with the experimental data. On the basis of the deviations results it is possible to conclude that five-parameter equation is more appropriate to satisfactorily reproduce the phase diagrams of the selected IL-based ABS, no matter the IL cation and potassium inorganic salt, in agreement with the findings reported by Deive et al. [31].

Table 1. Values of fitting parameters of correlation Equation (1) and standard deviation for $\mathrm{IL}+$ potassium inorganic salt $+\mathrm{H}_{2} \mathrm{O}$ at $298.15 \mathrm{~K}$.

\begin{tabular}{ccccccc}
\hline Equation 1 & $\boldsymbol{a}$ & $\boldsymbol{b}$ & $\boldsymbol{c}$ & $\boldsymbol{n}$ & $\boldsymbol{m}$ & $\boldsymbol{\sigma}$ \\
\hline \multirow{2}{*}{$\mathrm{C}_{2} \mathrm{C}_{1} \mathrm{im} \mathrm{C}_{1} \mathrm{SO}_{4}+\mathrm{K}_{2} \mathrm{CO}_{3}+\mathrm{H}_{2} \mathrm{O}$} & 112.84 & -0.3184 & $3.0 \times 10^{-5}$ & & & 0.499 \\
& 111.63 & -0.4100 & $3.8 \times 10^{-4}$ & 0.4 & 2.4 & 0.484 \\
\hline \multirow{2}{*}{$\mathrm{C}_{2} \mathrm{C}_{1} \mathrm{im} \mathrm{C}_{1} \mathrm{SO}_{4}+\mathrm{K}_{2} \mathrm{HPO}_{4}+\mathrm{H}_{2} \mathrm{O}$} & 80.00 & -0.2495 & $2.1 \times 10^{-5}$ & & & 0.315 \\
& 80.01 & -0.2648 & $7.4 \times 10^{-5}$ & 0.5 & 2.7 & 0.361 \\
\hline \multirow{2}{*}{$\mathrm{C}_{4} \mathrm{C}_{1} \mathrm{im} \mathrm{C}_{1} \mathrm{SO}_{4}+\mathrm{K}_{2} \mathrm{CO}_{3}+\mathrm{H}_{2} \mathrm{O}$} & 80.00 & -0.2969 & $5.0 \cdot \times 10^{-5}$ & & & 0.464 \\
& 80.00 & -0.3782 & $1.2 \times 10^{-4}$ & 0.4 & 2.8 & 0.463 \\
\hline \multirow{2}{*}{$\mathrm{C}_{4} \mathrm{C}_{1} \mathrm{im} \mathrm{C}_{1} \mathrm{SO}_{4}+\mathrm{K}_{2} \mathrm{HPO}_{4}+\mathrm{H}_{2} \mathrm{O}$} & 60.00 & -0.2156 & $5.3 \cdot \times 10^{-5}$ & & & 0.152 \\
& 30.61 & 0.0085 & $1.2 \times 10^{-3}$ & 1.0 & 2.2 & 0.146 \\
\hline \multirow{2}{*}{$\mathrm{P}_{4441} \mathrm{C}_{1} \mathrm{SO}_{4}+\mathrm{K}_{2} \mathrm{CO}_{3}+\mathrm{H}_{2} \mathrm{O}$} & 70.01 & -0.3191 & $2.7 \cdot \times 10^{-4}$ & & & 0.616 \\
& 71.28 & -0.1445 & $1.0 \times 10^{-3}$ & 0.9 & 2.4 & 0.243 \\
\hline \multirow{2}{*}{$\mathrm{P}_{4441} \mathrm{C}_{1} \mathrm{SO}_{4}+\mathrm{K}_{2} \mathrm{HPO}_{4}+\mathrm{H}_{2} \mathrm{O}$} & 80.00 & -0.3584 & $1.4 \cdot \times 10^{-4}$ & & & 0.335 \\
& 33.54 & 0.1417 & $2.4 \times 10^{-2}$ & 0.5 & 1.6 & 0.105 \\
\hline \multirow{2}{*}{$\mathrm{C}_{1} \mathrm{Py} \mathrm{C}_{1} \mathrm{SO}_{4}+\mathrm{K}_{2} \mathrm{CO}_{3}+\mathrm{H}_{2} \mathrm{O}$} & 100.01 & -0.2465 & $2.9 \cdot \times 10^{-5}$ & & & 0.999 \\
& 100.07 & -0.494 & $1.9 \times 10^{-2}$ & 0.7 & 1.3 & 0.717 \\
\hline \multirow{2}{*}{$\mathrm{C}_{1} \mathrm{Py} \mathrm{C}_{1} \mathrm{SO}_{4}+\mathrm{K}_{2} \mathrm{HPO}_{4}+\mathrm{H}_{2} \mathrm{O}$} & 70.00 & -0.1979 & $2.5 \cdot \times 10^{-5}$ & & & 0.456 \\
& 79.99 & -0.3226 & $1.5 \times 10^{-3}$ & 0.3 & 1.9 & 0.327 \\
\hline
\end{tabular}


Table 2. Values of fitting parameters of correlation Equation (2) and standard deviation for $\mathrm{IL}+$ potassium inorganic salt $+\mathrm{H}_{2} \mathrm{O}$ at $298.15 \mathrm{~K}$.

\begin{tabular}{ccccc}
\hline Equation 2 & $\boldsymbol{d}$ & $\boldsymbol{e}$ & $\boldsymbol{f}$ & $\boldsymbol{\sigma}$ \\
\hline $\mathrm{C}_{2} \mathrm{C}_{1} \mathrm{im} \mathrm{C}_{1} \mathrm{SO}_{4}+\mathrm{K}_{2} \mathrm{CO}_{3}+\mathrm{H}_{2} \mathrm{O}$ & -28.38 & 105.10 & -0.1494 & 0.988 \\
$\mathrm{C}_{2} \mathrm{C}_{1} \mathrm{im} \mathrm{C}_{1} \mathrm{SO}_{4}+\mathrm{K}_{2} \mathrm{HPO}_{4}+\mathrm{H}_{2} \mathrm{O}$ & -22.17 & 81.12 & -4.9460 & 0.468 \\
$\mathrm{C}_{4} \mathrm{C}_{1} \mathrm{im} \mathrm{C}_{1} \mathrm{SO}_{4}+\mathrm{K}_{2} \mathrm{CO}_{3}+\mathrm{H}_{2} \mathrm{O}$ & -13.60 & 44.82 & -10.0118 & 0.510 \\
$\mathrm{C}_{4} \mathrm{C}_{1} \mathrm{im} \mathrm{C}_{1} \mathrm{SO}_{4}+\mathrm{K}_{2} \mathrm{HPO}_{4}+\mathrm{H}_{2} \mathrm{O}$ & -21.04 & 74.61 & -3.1855 & 0.400 \\
$\mathrm{P}_{4441} \mathrm{C}_{1} \mathrm{SO}_{4}+\mathrm{K}_{2} \mathrm{CO}_{3}+\mathrm{H}_{2} \mathrm{O}$ & -16.08 & 46.51 & -4.4159 & 0.556 \\
$\mathrm{P}_{4441} \mathrm{C}_{1} \mathrm{SO}_{4}+\mathrm{K}_{2} \mathrm{HPO}_{4}+\mathrm{H}_{2} \mathrm{O}$ & -17.72 & 54.93 & -3.8697 & 0.309 \\
$\mathrm{C}_{1} \mathrm{Py} \mathrm{C}_{1} \mathrm{SO}_{4}+\mathrm{K}_{2} \mathrm{CO}_{3}+\mathrm{H}_{2} \mathrm{O}$ & -21.82 & 78.61 & -8.7861 & 0.617 \\
$\mathrm{C}_{1} \mathrm{Py} \mathrm{C}_{1} \mathrm{SO}_{4}+\mathrm{K}_{2} \mathrm{HPO}_{4}+\mathrm{H}_{2} \mathrm{O}$ & -31.56 & 122.26 & 2.8666 & 0.393 \\
\hline
\end{tabular}

A visual inspection of the standard deviations collected in Tables 1 and 2 allows concluding that three-parameters empirical Equation (1) is able to describe in a more suitable way the solubility data when the imidazolium-based ILs are involved. In contrast, the solubility data of phosphonium and pyridinium ILs (binodal curves closer to the origin) are better correlated by using the Equation (1). In the same line, the selected potassium inorganic salts also entail the same behavior, since a better description is attained for the strongest salting out agent $\left(\mathrm{K}_{2} \mathrm{HPO}_{4}\right)$ by using the Equation (2).

\subsection{Effect of Potassium Inorganic Salts on the ABS}

The addition of an appropriate amount of the selected potassium based-inorganic salts allows triggering phase segregation due to the competition of the salt for the water molecules in the presence of the IL. This competition is won by the salt; and then the solubility of the IL in water subsequently decreases. The consequence associated to this phenomenon is the formation of a top phase mostly made up of IL and a bottom phase enriched in the potassium salt.

The experimental phase diagrams plotted in $\mathrm{mol} / \mathrm{Kg}$ units and collected in Figure 1 indicate that different amounts of the selected salts are required for phase separation. $\mathrm{K}_{2} \mathrm{HPO}_{4}$ is the salt showing a stronger ability to form an immiscible area in the presence of the aqueous-IL mixtures. This salt-rank effect follows the Hofmeister series, which order ions according to their water structuring capacity. In this sense, it is possible to conclude that $\mathrm{CO}_{3}{ }^{2-}$ is the ion with the weakest interactions with water, thus leading to a smaller biphasic region. In contrast, the most kosmotropic $\mathrm{HPO}_{4}{ }^{2-}$ involves phase diagrams closer to the origin.

The molar entropy of hydration $\left(\Delta S_{\text {hyd }}\right)$ is a novel tool to appropriately explain the observed patterns. These values were used in a previous paper [32] to ascertain the segregation potential of inorganic salts. The $\Delta S_{\text {hyd }}$ data published in this recent paper $\left(\mathrm{HPO}_{4}{ }^{2-}=-272 \mathrm{~J} / \mathrm{molK}\right.$ and $\mathrm{CO}_{3}{ }^{2-}=-245 \mathrm{~J} / \mathrm{molK}$ ) allows one to validate the tendency followed by the inorganic salts, thus confirming the correlation between the IL molality and the $\Delta S_{\text {hyd. }}$.

\subsection{Effect of IL Family and Cation Size and on the ABS}

The capacity of the selected ILs to be promoted from the aqueous mixture to a top phase can be compared attending to the IL family and cation size. It can be observed that the larger immiscible area is obtained for the quaternary phosphonium based-ionic liquids, followed by pyridinium and 
imidazolium families $\left(\mathrm{P}_{4441}>\mathrm{C}_{4} \mathrm{Py}>\mathrm{C}_{\mathrm{n}} \mathrm{C}_{1} \mathrm{im}\right)$. The reason for this phase segregation behavior may lie in the different charge dispersion among families. Thus, while the charge in the imidazolium family is dispersed along the aromatic moiety, the pyridinium and phosphonium cations possess the charges more concentrated on the heteroatom (nitrogen and phosphorous, respectively), as also concluded Freire and coworkers [33]. In this sense, the absence of aromaticity in the phosphonium IL corroborates its higher ability to undergo phase segregation when the inorganic salts are added.

In general terms, the charge dispersion along the imidazolium moiety confers to these ILs the ability to form hydrogen bonds, thus they can be cosidrd as "good wat $r$ so v ts". Notwithstanding this statement, the ABS will be greatly influenced by the alkyl chain length of the imidazolium-based IL. In this case, ABS segregation capacity follows the order: $\mathrm{C}_{4} \mathrm{C}_{1} \mathrm{im} \mathrm{C}_{1} \mathrm{SO}_{4}>$ $\mathrm{C}_{2} \mathrm{C}_{1} \mathrm{im} \mathrm{C}_{1} \mathrm{SO}_{4}$ for both potassium-based inorganic salts. The explanation behind this trend is supported by the consideration that the solubility of ILs in water is strongly influenced by their molar volume. Larger cations have been considered to better segregate two phases than smaller cations, and then, the ABS formation depends on the size of the cation [33].

The phase behavior of each system can also be analyzed in terms of the EEV theory [34], which is based on the statement that each point of the solubility curve corresponds with a geometrically saturated solution of one solute in the presence of another one. The equation to which the experimental data were fitted is:

$$
\ln \left(V_{213}^{*} \frac{w_{2}}{M_{2}}+f_{213}\right)+V_{213}^{*} \frac{w_{1}}{M_{1}}=0
$$

being $V_{213}^{*}$ the scaled EEV of the salt, $f_{213}$ the volume fraction of unfilled effective available volume after tight packaging of salt molecules into the network of IL molecules in aqueous solutions, and $M_{1}$ and $M_{2}$, the molar mass of IL and salt, respectively.

The values of the EEV and $f_{213}$ are listed in Table 3 together with the standard deviations. From the data obtained it is possible to confirm all the above-mentioned conclusions, since the phosphonium-based ILs led to the highest values of EEV, and they can be salted out more easily by the potassium inorganic salts. The same trend is checked for the imidazolium ring containing the longest alkylchain, since doubling the number of carbon atoms involved doubling the EEV values. In the same vein, the most water structuring anion $\left(\mathrm{HPO}_{4}{ }^{2-}\right)$ led to higher values of $\mathrm{EEV}$ than $\mathrm{CO}_{3}{ }^{2-}$.

Table 3. Values of parameters of Effective Excluded Volume (EEV) and $f_{213}$ for $\mathrm{IL}+$ potassium inorganic salt $+\mathrm{H}_{2} \mathrm{O}$ at $298.15 \mathrm{~K}$.

\begin{tabular}{cccc}
\hline & $\boldsymbol{V}^{*}{ }_{\mathbf{1 2 3}} /(\mathrm{g} / \mathbf{m o l})$ & $\boldsymbol{f}_{\mathbf{2 1 3}}$ & $\boldsymbol{\sigma}$ \\
\hline $\mathrm{C}_{2} \mathrm{C}_{1} \mathrm{im} \mathrm{C}_{1} \mathrm{SO}_{4}+\mathrm{K}_{2} \mathrm{CO}_{3}+\mathrm{H}_{2} \mathrm{O}$ & 4.8 & 0.987 & 0.021 \\
$\mathrm{C}_{2} \mathrm{C}_{1} \mathrm{im} \mathrm{C}_{1} \mathrm{SO}_{4}+\mathrm{K}_{2} \mathrm{HPO}_{4}+\mathrm{H}_{2} \mathrm{O}$ & 7.3 & 0.984 & 0.014 \\
$\mathrm{C}_{4} \mathrm{C}_{1} \mathrm{im} \mathrm{C}_{1} \mathrm{SO}_{4}+\mathrm{K}_{2} \mathrm{CO}_{3}+\mathrm{H}_{2} \mathrm{O}$ & 8.0 & 0.983 & 0.046 \\
$\mathrm{C}_{4} \mathrm{C}_{1} \mathrm{im} \mathrm{C}_{1} \mathrm{SO}_{4}+\mathrm{K}_{2} \mathrm{HPO}_{4}+\mathrm{H}_{2} \mathrm{O}$ & 12.0 & 0.978 & 0.027 \\
$\mathrm{P}_{4441} \mathrm{C}_{1} \mathrm{SO}_{4}+\mathrm{K}_{2} \mathrm{CO}_{3}+\mathrm{H}_{2} \mathrm{O}$ & 20.0 & 0.973 & 0.028 \\
$\mathrm{P}_{4441} \mathrm{C}_{1} \mathrm{SO}_{4}+\mathrm{K}_{2} \mathrm{HPO}_{4}+\mathrm{H}_{2} \mathrm{O}$ & 30.0 & 0.962 & 0.018 \\
$\mathrm{C}_{1} \mathrm{Py} \mathrm{C}_{1} \mathrm{SO}_{4}+\mathrm{K}_{2} \mathrm{CO}_{3}+\mathrm{H}_{2} \mathrm{O}$ & 12.0 & 0.967 & 0.015 \\
$\mathrm{C}_{1} \mathrm{Py}_{1} \mathrm{SO}_{4}+\mathrm{K}_{2} \mathrm{HPO}_{4}+\mathrm{H}_{2} \mathrm{O}$ & 20.0 & 0.954 & 0.011 \\
\hline
\end{tabular}




\subsection{PCP Extraction}

Once the suitability of the proposed ILs to be salted out by the selected high charge density inorganic salts has been demonstrated, the systems allowing a greater immiscibility region (those with the $\mathrm{K}_{2} \mathrm{HPO}_{4}$ salt) were chosen to extract PCP as model pesticide. One of the outstanding characteristics of this contaminant is its easy dissolution in water, so it is essential to reduce the concentration levels of this contaminant in wastewater. Therefore, the final step of this work consisted of analyzing the affinity of PCP for the IL-rich phase. To our knowledge, this is the first time that IL-based ABS have been used for PCP extraction. One of the useful parameters often employed for characterizing the viability of a given separation process is the partition coefficient $(K)$ :

$$
K=\frac{[\mathrm{PCP}]_{\mathrm{IL}}}{[\mathrm{PCP}]_{\mathrm{w}}}
$$

where $[\mathrm{PCP}]_{\mathrm{IL}}$ and $[\mathrm{PCP}]_{\mathrm{w}}$ are the PCP concentration in the IL-rich phase and in the inorganic salt-rich phase, respectively.

In addition, the separation performance was analyzed in terms of extraction efficiency, $E(\%)$ :

$$
E(\%)=\left(\frac{\mathrm{m}_{\mathrm{PCP}}^{\mathrm{IL}}}{\mathrm{m}_{\mathrm{PCP}}}\right) \times 100
$$

where $\mathrm{m}_{\mathrm{PCP}}^{\mathrm{IL}}$ and $\mathrm{m}_{\mathrm{PCP}}$ are the PCP mass content in the IL-rich phase and total PCP mass, respectively.

In this work, different cations paired to the same anion were investigated and the interaction with the contaminant PCP indicates significant effects on the partition coefficient into the IL phase. The values of the partition coefficients and extraction efficiencies obtained for each system are shown in Table 4.

Table 4. Partition coefficients $K$ and extraction efficiency $E$ for IL $+\mathrm{K}_{2} \mathrm{HPO}_{4}+\mathrm{H}_{2} \mathrm{O}$ at $298.15 \mathrm{~K}$.

\begin{tabular}{ccc}
\hline System & $\boldsymbol{K}$ & $\boldsymbol{E}(\boldsymbol{\%})$ \\
\hline $\mathrm{C}_{2} \mathrm{C}_{1} \mathrm{im} \mathrm{C}_{1} \mathrm{SO}_{4}+\mathrm{K}_{2} \mathrm{HPO}_{4}+\mathrm{H}_{2} \mathrm{O}$ & 105 & 92 \\
$\mathrm{C}_{4} \mathrm{C}_{1} \mathrm{im} \mathrm{C}_{1} \mathrm{SO}_{4}+\mathrm{K}_{2} \mathrm{HPO}_{4}+\mathrm{H}_{2} \mathrm{O}$ & 138 & 94 \\
$\mathrm{P}_{4441} \mathrm{C}_{1} \mathrm{SO}_{4}+\mathrm{K}_{2} \mathrm{HPO}_{4}+\mathrm{H}_{2} \mathrm{O}$ & 1140 & 99 \\
$\mathrm{C}_{1} \mathrm{Py} \mathrm{C}_{1} \mathrm{SO}_{4}+\mathrm{K}_{2} \mathrm{HPO}_{4}+\mathrm{H}_{2} \mathrm{O}$ & 183 & 96 \\
\hline
\end{tabular}

From the partition data obtained it is clear that systems proposed are all suitable for the extraction of PCP. More specifically, the extraction capacity follows the sequence: $\mathrm{P}_{4441} \mathrm{C}_{1} \mathrm{SO}_{4}>\mathrm{C}_{1} \mathrm{Py} \mathrm{C}_{1} \mathrm{SO}_{4}>$ $\mathrm{C}_{4} \mathrm{C}_{1}$ im $\mathrm{C}_{1} \mathrm{SO}_{4}>\mathrm{C}_{2} \mathrm{C}_{1} \mathrm{im} \mathrm{C}_{1} \mathrm{SO}_{4}$. These results match those previously obtained for the ILs ability to form greater immiscibility regions. Furthermore, the observed pattern is in agreement with the results of selectivity reported recently by Pilli et al. (2012) [3], thus confirming the suitability of the phosphonium- based ILs for the implementation of this kind of remediation processes. On the other hand, the analysis of the extraction efficiencies points the ILs based on phosphonium cation as promising candidates to remove more than $99 \%$ of the pesticide present in a wastewater effluent.

The effect of the $\mathrm{pH}$ in the partition coefficient of PCP has been investigated with the purpose to obtain a relationship with the chemical structures of the ILs. In this sense, $\mathrm{pH}$ could be considered as a 
preliminary data to predict the segregation capacity of an organic compound in the presence of aqueous solutions of ILs. The experimental data of $\mathrm{pH}$ from the IL and water -rich phases indicate that the mixtures are basic (varies from 8.5 to 9.6, data listed in Table S2) for all the selected ternary mixtures. On the other hand, PCP is present as a neutral (acidic medium) or negative mono (basic medium) charged species when the $\mathrm{pH}$ is increased (Chemspider chemical database data [35]). Taking this into consideration, it is possible to conclude that the water content and the hydrogen bonds with the $\mathrm{C}_{1} \mathrm{SO}_{4}{ }^{-}$anion govern the partition coefficients. This scenario would consequently influence the anionic form of PCP in the basic aqueous mixture, causing it to present a high hydrophobicity and also a strong electrostatic interaction with the cationic part of the phosphonium based-IL, leading to the pesticide being salted out to the charged IL-rich phase.

\section{Experimental Section}

\subsection{Materials}

$\mathrm{C}_{4} \mathrm{C}_{1}$ im $\mathrm{C}_{1} \mathrm{SO}_{4}$ [36] and $\mathrm{C}_{1} \mathrm{Py}_{1} \mathrm{CO}_{4}$ [37] were synthesized according to the procedure detailed elsewhere. $\mathrm{C}_{2} \mathrm{C}_{1}$ im $\mathrm{C}_{1} \mathrm{SO}_{4}$ was purchased from Merck and $\mathrm{P}_{441} \mathrm{C}_{1} \mathrm{SO}_{4}$ was kindly donated by Cytec. All the ILs were characterized by its NMR spectra and positive FABMS (FISONS VG AUTOSPEC mass spectrometer) with purity better than $99 \%$. The water content was reduced to values less than $0.02 \%$ by means of vacuum $(0.2 \mathrm{~Pa})$ and moderate temperature $(333.15 \mathrm{~K})$ during several days. 756 Karl Fisher coulometer was used to determine the IL-water content prior to their use. Dipotassium hydrogen phosphate $\left(\mathrm{K}_{2} \mathrm{HPO}_{4}\right)$, and potassium carbonate $\left(\mathrm{K}_{2} \mathrm{CO}_{3}\right)$ were supplied by Sigma-Aldrich (Madrid, Spain) with purity higher than 98\%, and were used as received, without further purification. The information related to the selected ILs and the potassium-based inorganic salts is collected in Table 5.

Table 5. Materials provenance and purities.

\begin{tabular}{cccc}
\hline Chemical name & Supplier & Mass fraction purity & Method of analysis \\
\hline $\mathrm{C}_{4} \mathrm{C}_{1} \mathrm{im} \mathrm{C}_{1} \mathrm{SO}_{4}$ & Synthesized & 0.99 & NMR and positive FAMBS \\
$\mathrm{C}_{2} \mathrm{C}_{1} \mathrm{im} \mathrm{C}_{1} \mathrm{SO}_{4}$ & Merck & 0.99 & None \\
$\mathrm{C}_{1} \mathrm{Py} \mathrm{C}_{1} \mathrm{SO}_{4}$ & Synthesized & 0.99 & NMR and positive FAMBS \\
$\mathrm{P}_{4441} \mathrm{C}_{1} \mathrm{SO}_{4}$ & Cytec & 0.99 & None \\
$\mathrm{K}_{2} \mathrm{CO}_{3}$ & Sigma-Aldrich & 0.98 & None \\
$\mathrm{K}_{2} \mathrm{HPO}_{4}$ & Sigma-Aldrich & 0.98 & None \\
\hline
\end{tabular}

\subsection{Solubility Curves Determination}

The phase diagrams of the ABS were carried out by means of the cloud point titration method [4] at 298.15 K. A known amount of salt was added to the different IL aqueous solutions until the detection of turbidity, and then followed by the drop-wise addition of ultra-pure water until a clear monophasic region was achieved. The system was always operating under constant stirring. The ternary system compositions were determined by the weight quantification of all components within an uncertainty of $\pm 10^{-4} \mathrm{~g}$. The temperature was controlled with a F200 ASL digital thermometer with an uncertainty of $\pm 0.01 \mathrm{~K}$. 


\subsection{PCP Extraction}

PCP extraction started with the addition of the pollutant (at a concentration lower than $15 \mathrm{mg} / \mathrm{L}$ ) to a binary mixture (water and IL) within the miscibility region of known mass percentage and the salting out agent was added until reaching the phase segregation. The partition was carried out in graduated tubes at $298.15 \mathrm{~K}$. The mixture was stirred vigorously and left to settle for $24 \mathrm{~h}$ to ensure a complete separation of the layers. The two phases were then carefully separated and the pesticide was quantified in both the top and bottom phases by liquid chromatography measurements. Possible interferences of the ILs were discarded by measuring each phase without PCP.

\subsection{PCP Analysis}

PCP concentrations in two phases were analyzed by reversed-phase high performance liquid chromatography (HPLC) equipped with a XDB-C8 reverse-phase column $(150 \times 4.6 \mathrm{~mm}$ i.d., $5 \mu \mathrm{m})$ with its corresponding guard column. The HPLC system was a HITACHI LaChrom Elite equipped with a quaternary pump (L2130) and photodiode array UV/Vis detector (280 nm). Prior to injection, the samples were filtered through a $0.45-\mu \mathrm{m}$ Teflon filter. The injection volume was s t at $0 \mu \mathrm{L}$, a d the isocratic eluent (90:10 methanol/water) was pumped at a rate of $0.8 \mathrm{~mL} / \mathrm{min}$ for $6 \mathrm{~min}$.

\section{5. pH Determination}

The $\mathrm{pH}$ of the IL and water-rich phases was carried out at $298.15 \mathrm{~K}$ using a 2100 series $\mathrm{pH}$ meter (OAKTON instruments, Nijkerk, The Netherlands). The calibration of the $\mathrm{pH}$ meter was carried out with three buffers ( $\mathrm{pH}$ values of 4.00, 7.00 and 9.00). The $\mathrm{pH}$ data listed in Table S1 were determined for the upper and bottom phases after the different PCP partition experiments.

\section{Conclusions}

In this work, the efficiency of several methylsulfate-based ILs as PCP extraction agents was investigated for the first time. It was demonstrated that the combination of $\mathrm{K}_{2} \mathrm{HPO}_{4}$ with the selected ILs involved binodal curves closer to the origin, so it was selected for the evaluation of the separation of PCP in terms of partition coefficients and extraction efficiency. The analysis of the obtained data revealed a greater ability of phosphonium-based ILs for the separation of PCP, reaching extraction efficiencies of higher than $99 \%$ and partition coefficients higher than 1000 . These data are promising for further implementation of the process on a larger scale.

\section{Acknowledgments}

F. Moscoso thanks FCT for a postdoctoral grant (code SFRH/BPD/86887/2012). F.J. Deive acknowledges Xunta de Galicia for funding through an Isidro Parga Pondal contract.

\section{Conflicts of Interest}

The authors declare no conflict of interest. 


\section{References}

1. Registration Eligibility Decision for Pentachlorophenol. Available online: http://www.epa.gov/oppsrrd1/REDs/pentachlorophenol_red.pdf (accessed on 12 October 2013).

2. Basic Information about Pentachlorophenol in Drinking Water. Available online: http://water.epa.gov/drink/contaminants/basicinformation/pentachlorophenol.cfm (accessed on 12 October 2013).

3. Pilli, S.R.; Banerjee, T.; Mohanty, K. Extraction of pentachlorophenol and dichlorodiphenyl trichloroethane from aqueous solutions using ionic liquids. J. Ind. Eng. Chem. 2012, 18, 1983-1996.

4. Albertsson, P.A. Partitioning of Cell Particles and Macromolecules; John Wiley and Sons: New York, NY, USA, 1986.

5. Deive, F.J.; Rodríguez, A.; Pereiro, A.B.; Araújo, J.M.M.; Longo, M.A.; Coelho, M.A.Z.; Canongia Lopes, J.N.; Esperança, J.M.S.S.; Rebelo, L.P.N.; Marrucho, I.M. Ionic liquid-based aqueous biphasic system for lipase extraction. Green Chem. 2011, 13, 390-396.

6. Ulloa, G.; Coutens, C.; Sánchez, M.; Sineiro, J.; Fábregas, J.; Deive, F.J.; Rodríguez, A.; Núñez, M.J. On the double role of surfactants as microalga cell lysis agents and antioxidants extractants. Green Chem. 2012, 14, 1044-1051.

7. Luechau, F.; Ling, T.C.; Lyddiatt, A. Partition of plasmid DNA in polymer-salt aqueous two-phase systems. Sep. Purif. Technol. 2009, 66, 397-404.

8. Bulgariu, L.; Bulgariu, D. Extraction of metal ions in aqueous polyethylene glycol-inorganic salt two-phase systems in the presence of inorganic extractants: Correlation between extraction behaviour and stability constants of extracted species. J. Chromatogr. A 2008, 1196, 117-124.

9. Mokhtarani, B.; Karimzadeh, R.; Amini, M.H.; Manesh, S.D. Partitioning of Ciprofloxacin in aqueous two-phase system of poly(ethylene glycol) and sodium sulphate. Biochem. Eng. J. 2008, 38, 241-247.

10. Martins, J.P.; dos Reis Coimbra, J.S.; Oliveira, F.C.; Sanaiotti, G.; da Silva, C.A.S.; Mendes da Silva, L.H.; da Silva, M.C.H. Liquid-liquid equilibrium of aqueous two-phase system composed of poly(ethylene glycol) 400 and sulfate salts. J. Chem. Eng. Data 2010, 55, 1247-1251.

11. Zafarani-Moattar, M.T.; Hamzehzadeh, S. Partitioning of amino acids in the aqueous biphasic system containing the water-miscible ionic liquid 1-butyl-3-methylimidazolium bromide and the water-structuring salt potassium citrate. Biotechnol. Prog. 2011, 27, 986-997.

12. Zafarani-Moattar, M.T.; Hamzehzadeh, S. Salting-out effect, preferential exclusion, and phase separation in aqueous solutions of chaotropic water-miscible ionic liquids and kosmotropic salts: Effects of temperature, anions, and cations. J. Chem. Eng. Data 2010, 55, 1598-1610.

13. Gutowski, K.E.; Broker, G.A.; Willauer, H.D.; Huddleston, J.G.; Swatloski, R.P.; Holbrey, J.D.; Rogers, R.D. Controlling the aqueous miscibility of ionic liquids: Aqueous biphasic systems of water-miscible ionic liquids and water-structuring salts for recycle, metathesis, and separations. J. Am. Chem. Soc. 2003, 125, 6632-6633. 
14. Freire, M.G.; Carvalho, P.J.; Silva, A.M.S.; Santos, L.M.N.B.F.; Rebelo, L.P.N.; Marrucho, I.M.; Coutinho, J.A.P. Ion specific effects on the mutual solubilities of water and hydrophobic ionic liquids. J. Phys. Chem. B 2009, 113, 202-211.

15. Han, J.A.; Wang, Y.; Yu, C.L.; Li, C.X.; Yan, Y.S.; Liu, Y.; Wang, L.A. Separation, concentration and determination of chloramphenicol in environment and food using an ionic liquid/salt aqueous two-phase flotation system coupled with high-performance liquid chromatography. Anal. Chim. Acta 2011, 685, 138-145.

16. Freire, M.G.; Neves, C.M.S.S.; Silva, A.M.S.; Santos, L.M.N.B.F.; Marrucho, I.M.; Rebelo, L.P.N.; Shah, J.K.; Maginn, E.J.; Coutinho, J.A.P. ${ }^{1} \mathrm{H}$ NMR and molecular dynamics evidence for an unexpected interaction on the origin of salting-in/salting-out phenomena. J. Phys. Chem. B 2010, 114, 2004-2014.

17. Bösmann, A.; Datsevich, L.; Jess, A.; Lauter, A.; Schmitz, C.; Wasserscheid, P. Deep desulfurization of diesel fuel by extraction with ionic liquids. Chem. Commun. 2001, doi: 10.1039/B108411A.

18. Plechkova, N.V.; Seddon, K.R. Applications of ionic liquids in the chemical industry. Chem. Soc. Rev. 2008, 37, 123-150.

19. Earle, M.J.; Esperança, J.M.S.S.; Gilea, M.A.; Canongia Lopes, J.N.; Rebelo, L.P.N.; Magee, J.W.; Seddon, K.R.; Widegren, J.A. The distillation and volatility of ionic liquids. Nature 2006, 439, 831-834.

20. Smiglak, M.; Reichert, W.M.; Holbrey, J.D.; Wilkes, J.S.; Sun, L.T.; Thrasher, J.S.; Kirichenko, K.; Singh, S.; Katritzky, A.R.; Rogers, R.D. Combustible ionic liquids by design: Is laboratory safety another ionic liquid myth? Chem. Commun. 2006, 24, 2554-2556.

21. Pereiro, A.B.; Rodriguez, A. Azeotrope-breaking using [BMIM] $\left[\mathrm{MeSO}_{4}\right]$ ionic liquid in an extraction column. Sep. Purif. Technol. 2008, 62, 733-738.

22. Petkovic, M.; Seddon, K.R.; Rebelo, L.P.N.; Pereira, C.S. Ionic liquids: A pathway to environmental acceptability. Chem. Soc. Rev. 2011, 40, 1383-1403.

23. Deive, F.J.; Rodríguez, A.; Varela, A.; Rodrígues, C.; Leitão, M.C.; Houbraken, J.A.M.P.; Pereiro, A.B.; Longo, M.A.; Sanromán, M.A.; Samson, R.A.; et al. Impact of ionic liquids on extreme microbial biotypes from soil. Green Chem. 2011, 13, 687-696.

24. Bekou, E.; Dionysiou, D.D.; Qian, R.-Y.; Botsaris, G.D. Extraction of chlorophenols from water using room temperature ionic liquids. ACS Symp. Ser. 2003, 856, 544-560.

25. Khodadoust, A.P.; Chandrasekaran, S.; Dionysiou, D.D. Preliminary assessment of imidazolium-based room-temperature ionic liquids for extraction of organic contaminants. Environ. Sci. Technol. 2006, 40, 2339-2345.

26. Fan, J.; Fan, Y.; Pei, Y.; Wu, K.; Wang, J.; Fan, M. Solvent extraction of selected endocrine-disrupting phenols using ionic liquids. Sep. Purif. Technol. 2008, 61, 324-331.

27. Katsuta, S.; Nakamura, K.; Kudo, Y.; Takeda, Y.; Kato, H. Partition behavior of chlorophenols and nitrophenols between hydrophobic ionic liquids and water. J. Chem. Eng. Data 2011, 56, 4083-4089.

28. Gomez, E.; Calvar, N.; Dominguez, A.; Macedo, E.A. Synthesis and temperature dependence of physical properties of four pyridinium-based ionic liquids: Influence of the size of the cation. J. Chem. Thermodyn. 2010, 42, 1324-1329. 
29. Ventura, S.P.M.; Sousa, S.G.; Serafim, L.S.; Lima, A.S.; Freire, M.F.; Coutinho, J.A.P. Ionic-liquid-based aqueous biphasic systems with controlled $\mathrm{pH}$ : The ionic liquid anion effect. J. Chem. Eng. Data 2012, 57, 507-512.

30. Wang, Y.; Han, J.; Liua, J.; Hua, Y.; Shenga, C.; Wua, Y. Liquid-liquid equilibrium phase behavior of iminazolium-based ionic liquid aqueous two-phase systems composed of 1-alkyl-3-methyl imidazolium tetrafluoroborate and different electrolytes $\mathrm{ZnSO}_{4}, \mathrm{MgSO}_{4}$ and $\mathrm{Li}_{2} \mathrm{SO}_{4}$ at $298.15 \mathrm{~K}$ : Experimental and correlation. Thermochim. Acta 2013, 557, 68-76.

31. Deive, F.J.; Rivas, M.A.; Rodríguez, A. Sodium carbonate as phase promoter in aqueous solutions of imidazolium and pyridinium ionic liquids. J. Chem. Thermodyn. 2011, 43, 1153-1158.

32. Shahriari, S.; Neves, C.M.S.S.; Freire, M.G.; Coutinho, J.A.P. Role of the hofmeister series in the formation of ionic-liquid-based aqueous biphasic systems. J. Phys. Chem. B 2012, 116, 7252-7258.

33. Freire, M.G.; Cláudio, A.F.M.; Araújo, J.M.M.; Coutinho, J.A.P.; Marrucho, I.M.; Canongia Lopes, J.N.; Rebelo, L.P.N. Aqueous biphasic systems: A boost brought about by using ionic liquids. Chem. Soc. Rev. 2012, 41, 4966-4995.

34. Guan, Y.; Lilley, T.H.; Treffy, T.E. A new excluded volume theory and its application to the coexistence curves of aqueous polymer two-phase systems. Macromolecules 1993, 26, 3971-3979.

35. The Free Chemical Database. Available online: http://www.chemspider.com (accessed on 12 October 2013).

36. Pereiro, A.B.; Santamarta, F.; Tojo, E.; Rodríguez, A.; Canosa, J.; Tojo, J. Temperature dependence of physical properties of ionic liquid 1,3-dimethylimidazolium methyl sulphate. J. Chem. Eng. Data 2006, 51, 952-954.

37. Pereiro, A.B.; Verdía, . o o, . odrg , A. Physical properties of 1-butyl-3-methylimidazolium methyl sulfate as a function of temperature. J. Chem. Eng. Data 2007, 52, 377-380.

(C) 2013 by the authors; licensee MDPI, Basel, Switzerland. This article is an open access article distributed under the terms and conditions of the Creative Commons Attribution license (http://creativecommons.org/licenses/by/3.0/). 